\title{
Implementation of Quick Response to Customer Relationship Management System Based on Mobile Application
}

\author{
Ali Ibrahim ${ }^{1}$, Akbar Alzaini ${ }^{2}$, Akbar Wiranata $^{3}$, Hanum Sabrina A.J ${ }^{4}$, \\ Ikamartha Dwazar $^{5}$, Reza Rio Saputra ${ }^{6}$
}

Ialiibrahim@unsri.ac.id, Informatics Engineering, Faculty of Computer Science, Universitas Sriwijaya, Indonesia

${ }_{2}^{2}$ akbaralzaini@gmail.com, Information System Program, Faculty of Computer Science, Sriwijaya University, Indonesia

${ }^{3}$ akbarwiranata45@gmail.com, Information System Program, Faculty of Computer Science, Sriwijaya University, Indonesia

${ }_{4}^{4}$ hanumsabrina16@gmail.com,Information System Program, Faculty of Computer Science, Sriwijaya University, Indonesia

${ }^{5}$ marthadwazar@gmail.com, Information System Program, Faculty of Computer Science, Sriwijaya University, Indonesia

${ }^{6}$ reza.rio97@gmail.com, Information System Program, Faculty of Computer Science, Sriwijaya

University, Indonesia

*Corespondent author: aliibrahim@unsri.ac.id

\begin{abstract}
Service improvement is crucial in companies, organizations or business that implement CRM which will increase the number of customers/visitors and form loyalty to the company. In restaurant context, many only focus on the food taste to convince customers to return to the restaurants, but pay a little attention to the overall service aspects. $78 \%$ of the respondents we sampled experienced problems when ordering food. After the survey of the use of QR code at Kedai Keji, it was found that $88.2 \%$ of respondents agreed that food ordering was more effective. 83.8 respondents stated that this application could minimize errors, and $91.2 \%$ of them mentioned that they felt comfortable for the service when using this application.
\end{abstract}

Keywords: CRM, QR code, android

\section{Introduction}

Service improvement is very important for companies, organizations or business that interact with customers to increase the number of customers/visitors and establish loyalty to the company/organization/business. Satisfaction with customers is something that should be a concern of a company, such as restaurants. The interactions occurring through this technology are likely to influence a salesperson's communication with customers. Thus, it is a must that precise information is relayed through the most appropriate mechanism. To accomplish this, salespeople must be able to communicate new information and correctly determine what 
information will be most useful to the customer [1]. The first impression of the customers is very important so that they feel comfortable and have a good impression which will make them go back to the restaurant. However, many restaurants only prioritize the taste of food to convince them to return, but pay less attention to the overall service aspects, especially the things that deal directly with customers, such as waiters, cashiers, and others where mistakes that seem trivial often happen. The examples are a waiter's mistake who incorrectly records orders made by the customers. The other examples are waiters who do not know the details of a good drink or food from the menu, lack of coordination with the the kitchen for the availability of the menu, and let customers to wait for food that is not available. Those will greatly disrupt the customers' comfort and leave a bad impression resulting in customers not wanting to go back to the restaurant. Therefore, the researchers conducted this research which can be one of the alternative solutions to overcome existing data inaccuracies. In addition, it can take advantage of new opportunities to attract more customers interest if they can directly interact and implement technology as they make an order so that they can have different and unique experience when they visit the restaurants.

\section{LITERATURE REFERENCES}

\section{Customer Relationship Management (CRM)}

Customer Relationship Management (CRM) is currently one of the strategies used by companies to better understand their customers, so that the companies can provide the best service and foster better long term relationships with their customers. Experts argue that Customer Relationship Management (CRM) is an approach that views customers as the core of their business and the success of a company depends on how they manage their relationships effectively [2]. Customer Relationship Management is defined as a business strategy. It is considered to be strongly related to the principles of relationship marketing and is based on a solid orientation of the whole organization on clients. CRM assumes developing and maintaining long term relationships with strategic clients of the company [3].

In this case study, CRM was used in the restaurant to help retaining customers and made it easy and attractive to customers to become loyal to the restaurant.

\section{(Quick Response) QR Code}

QR codes are storage systems that use a dot-matrix or two-dimensional bar code developed by Denso Wave that can be printed or shown on a screen and are interpreted by a special reader. The use of QR code in mobile application gives good, convenient, beneficial and interesting attitude towards QR. The success of QR mobile payment system technology relies on joint participation from multiple stakeholders, including consumers, merchants, network operators, device manufacturers, financial services, and software and technology providers [4]. With some analysis of the problems described, ordering food and beverage menus can be more optimal and seem attractive. It will provide different experience compared to the other restaurants if done using QR code technology where it will be equipped with detailed information on the menu so that customers can find out the available food directly and avoid the waiter who doesn't know the whole menu details. The appearance of this system will also be user friendly so that the customer does not have difficulties in ordering the food or drink. The customers simply direct their mobile camera to the QR code provided at the menu table.

\begin{abstract}
Android
Android is a Linux based operating system designed for touch screens mobile devices such as smartphones and tablets. Android is an open source operating system, and Google releases the code under the Apache License. The code with open source and licenses on Android allows the software to be modified freely and distributed by device makers, wireless operators, and application developers. In addition, Android has a large number of community application developers (apps) that expand the functionality of the device, generally written in a customized version of the Java programming language [5].
\end{abstract}

\section{Methodology}

This study was done by collecting data, analyzing the problems and opportunities that existed with reference to the research of qualified journals where the journals had relevance to the topic and discussion in this research. Then, there was also quantitative approach with surveys and questionnaires that took samples by using random sampling methods from the visitors of Kedai Keji restaurant. The population in this study was all visitors who visited Kedai Keji on $1^{\text {st }}-3^{\text {rd }}$ April 
2019. With an average number of visitors 27 people per day, the population in this study was 81 people. With that the number of samples can be determined by the formula:

$$
\begin{aligned}
& n=\frac{N}{1+N \cdot e^{2}} \\
& n=\frac{81}{1+81 \cdot(0,05)^{2}} \\
& n=68
\end{aligned}
$$

Information :

$\mathrm{n}=$ number of samples

$\mathrm{N}=$ population

$\mathrm{e}=$ error tolerance limit $(5 \%)$

With this formula, it can be concluded that we can use a minimum of 68 people as sample. This survey used 9 questions that represented the variable customers satisfaction towards the use of this application in Kedai Keji.

\section{RESULTS AND DISCUSSION}

We conducted surveys to ensure that the customers problems we analyzed were the same as those that occurred in the field. From the questionnaire and interview data, the results of the people who experienced problems when ordering food were $78 \%$ of 60 respondents from 8 questions. The problem was, among other things, the respond of the waiter to customers orders. It was caused by the number of customers which was too big for the waiter. In this study case there were 2 waiters for 46 chairs for customers including those who ordered take aways. Since the customers needed longer time to wait when the waiter had to respond to the other customers and the menu listed did not provide the details and significant information about the products, the customers had to ask the waiters. However, there was a possibility that the waiter didn't have know the detailed information about all of the menus. Those responds and customers' feeling would affect the relationship between them and the restaurant. It would give stigma and assumption from the customers to the restaurant how professional they are in serving them. So it can be concluded that customers satisfaction with the restaurant's waiters' service is not good and this can be a problem.

Based on the survey and questionnaire when the customers ordered using the menus in the application with QR codes, we obtained results stating that $88.2 \%$ of them who had tried to order using this application said it was more effective. For ease of application, $77.9 \%$ of respondents stated that this application was easy to understand. $88.2 \%$ respondents mentioned that this application had the menu information that the customers wanted. $75 \%$ customers stated that this application shortened the ordering time and 83.8 respondents said that this application could minimize errors made by waiters when taking the orders. $80.9 \%$ of customers felt a new experience in ordering food when they tried this application. Finally, 91.2\% of respondents stated comfort in service when using this application.

Table 1. The results of food ordering application using QR code questionnaire

\begin{tabular}{|c|c|c|c|}
\hline \multicolumn{1}{|c|}{ Question } & Yes & No & Maybe \\
\hline $\begin{array}{c}\text { 1. Do you think ordering food using the QR code } \\
\text { application makes it more effective? }\end{array}$ & $88,2 \%$ & $4,4 \%$ & $7,40 \%$ \\
\hline $\begin{array}{c}\text { 2. Do you think the application is easy to read? } \\
\text { 3. Is ordering using an application better than manual } \\
\text { ordering? } \quad \text { Do you think the application provides menu information }\end{array}$ & $88,2 \%$ & $1,5 \%$ & $10,3 \%$ \\
\hline $\begin{array}{c}4 . \quad 7,5 \% \\
\text { that you want? }\end{array}$ & $1,5 \%$ & $25,0 \%$ \\
\hline $\begin{array}{c}\text { D. Does ordering food using this application make your } \\
\text { order time shorter? }\end{array}$ & $75,0 \%$ & $1,5 \%$ & $23,5 \%$ \\
\hline
\end{tabular}




\begin{tabular}{|c|c|c|c|}
\hline $\begin{array}{c}\text { 6. Can using this application minimize errors in ordering } \\
\text { food? }\end{array}$ & $83,8 \%$ & $0 \%$ & $16,2 \%$ \\
\hline $\begin{array}{c}\text { 7. Does using the application in ordering food add to your } \\
\text { new experience? }\end{array}$ & $80,9 \%$ & $2,9 \%$ & $16,2 \%$ \\
\hline $\begin{array}{c}\text { 8. Does the use of this application make you comfortable so } \\
\text { that you feel like going back to the restaurant? }\end{array}$ & $91,2 \%$ & $1,4 \%$ & $7,4 \%$ \\
\hline
\end{tabular}

Researches about QR codes as helping aid in food ordering use a CRM approach to increase customers and waiters satisfaction with customers. From this study, we would examine whether a food ordering system with QR codes using CRM approaches will increase customers satisfaction with restaurant services. The result of this study is a software that will be used in restaurants and food menus equipped with QR codes. With this research, it can increase the number of customers by offering food ordering with new methods and paying close attention to customers satisfaction.

\section{SUMMARY}

Based on the results, the existence of a created system could improve services to customers. This was agreed by $83.8 \%$ of respondents. Then, the results of this study made it easy for customers to order food and the restaurant could supervise and obtain customers' ordering data for further analysis.

\section{REFERENCES}

[1] A. A. Alalwan, N. P. Rana, Y. K. Dwivedi, and R. Algharabat, "Social media in marketing: A review and analysis of the existing literature," Telemat. Informatics, vol. 34, no. 7, pp. 1177-1190, 2017.

[2] M. Anshari, Y. Alas, N. Yunus, N. I. Sabtu, and M. H. Hamid, "Social customer relationship management and student empowerment in online learning systems," Int. J. Electron. Cust. Relatsh. Manag., vol. 9, no. 2-3, pp. 104-121, 2015.

[3] C. A. Elena, "Social Media-A strategy in developing customer relationship management," Procedia Econ. Financ., vol. 39, pp. 785-790, 2016.

[4] F. Liébana-Cabanillas, I. Ramos de Luna, and F. J. Montoro-Ríos, "User behaviour in QR mobile payment system: the QR Payment Acceptance Model," Technol. Anal. Strateg. Manag., vol. 27, no. 9, pp. 1031-1049, 2015.

[5] D. R. Rahadi, "Usability measurement system using a questionnaire on an android application,” J. Sist. Inf., vol. 6, no. 1, 2014. 